\title{
Master of electrons and photons
}

\author{
Nikola Tesla is known for his work on alternating current power systems, induction motors and wireless \\ transmission but he is also an unsung hero of research into X-rays and light sources.
}

Next month, on 10 July to be exact, would have been Nikola Tesla's 159th birthday. The surname of the Serbian-American inventor extraordinaire typically kindles thoughts of polyphase alternating current power systems, high-voltages and 'lightning', wireless telegraphy or the unit of magnetic field strength, which was named in his honour 17 years after his death in 1943. Less well known is that Tesla also made important contributions to photonics, related to the understanding of electromagnetic wave propagation, $\mathrm{X}$-ray sources and imaging techniques, fluorescent tubes, phosphorescence and incandescence.

Many of Tesla's ideas were ahead of their time. In 1898 he unveiled a 'teleautomaton' aquatic vehicle (www.tfcbooks.com/ patents/0613809.htm) at an exhibition at Madison Square Garden ${ }^{1,2}$ that seemed to respond to commands to move, stop or turn. Perhaps equally unbelievable at the time was that Tesla had installed a battery, motor and the necessary circuitry in the boat to radio-control its movement. A submarine version was later demonstrated but Tesla apparently received little commercial or military interest in either version. More than a century later, with the advent of drone technology, Tesla is now being called the father of unmanned vehicle technology ${ }^{3}$.

\section{Many of Tesla's ideas were ahead of their time.}

Tesla contributed to a number of other fields not automatically associated with his name, such as his work on gas turbines and aircraft vertical take-off and landing schemes, which he patented in 1928 . Perhaps more relevant to the readership of Nature Photonics is the fact that Tesla didn't only work with low-frequency electromagnetism but also with higherfrequency phenomena.

The great German physicist Wilhelm Röntgen was the first to systematically study $\mathrm{X}$-rays and is credited with their discovery in 1895 . However, others experimenting with Crookes tubes had observed some of the effects of X-rays. In 1894 Tesla reportedly began investigating $\mathrm{X}$-rays after noticing damaged film ${ }^{4}$. Tesla may even have inadvertently made an X-ray

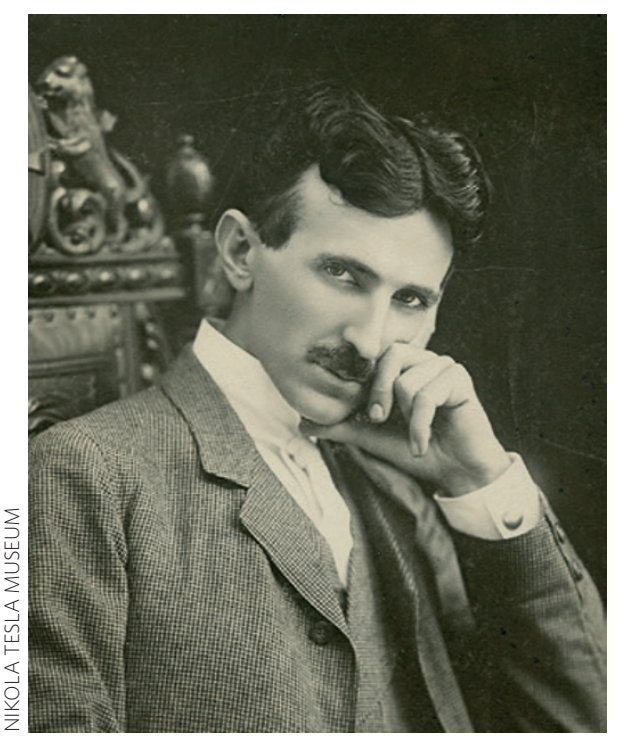

at ordinary pressures. Tesla had already developed high-frequency fluorescent bulbs in the early 1890s.

Tesla's name may have edged towards obscurity after his death but in recent years he has experienced a resurgence in appreciation and popularity. This is partly because the importance and avant-garde nature of his work still has significance after a century. Also, some of his claims and ideas lend themselves well to science fiction (for example, mechanical oscillators for demolishing buildings using resonance, and 'death rays' based on particle acceleration). He is also well known for expressing that he toiled for humanity rather than financial gain (in particular with regards to 'free' energy) and for this the internet now loves him. A music video describing his achievements and attitudes has over 31 million views to date (www.youtube. com/watch?v=gJ1Mz7kGVf0). A 2012 crowd-funding internet campaign raised US $\$ 1.4$ million to purchase the property of Tesla's former laboratory in Wardenclyffe, Shoreham, New York, for preservation. A similar effort in 2014 raised a further US\$518,000 in one month towards building a museum at the site.

For those wishing to know more about this astonishing figure there are excellent books documenting Tesla's life $\mathrm{e}^{1,2}$ and his lectures and patents can be read online ${ }^{5}$. The Nikola Tesla Museum in Belgrade has a large photo collection, original documents, Tesla's ashes in a spherical urn (Tesla's favourite geometry) and a replica of the radio-controlled boat. There are also important sites in Colorado Springs where Tesla worked on wireless telegraphy - it is there that the famous multiple exposure picture of Tesla casually reading a book with 'lightning' about him arcing across 7 million volts of potential was captured. On the internet, you can even buy a Tesla turbine and other kits.

References

1. Seifer, M. J. Wizard: The Life and Times of Nikola Tesla (Citadel Press, 2001)

2. Carlson, W. B. Tesla: Inventor of the Electrical Age (Princeton Univ. Press, 2013).

3. Weber, A. Nikola Tesla: Father of Unmanned Vehicle Technology. Assembly (26 April 2010); http://go.nature.com/F6SXjJ

4. Hrabak, M. et al. RadioGraphics 28, 1189-1192 (2008).

5. Twenty-first Century Books http://www.tfcbooks.com/ tesla/1893-02-24.htm (2013). 